\title{
Combined Spinal Epidural Anesthesia and Analgesia
}

\author{
Dusica Stamenkovic ${ }^{1}$ and Menelaos Karanikolas ${ }^{2}$ \\ ${ }^{1}$ Department of Anesthesiology, Military Medical Academy, Belgrade, \\ 2Department of Anesthesiology, Washington University School of Medicine, St. Louis, \\ ${ }^{1}$ Serbia \\ 2USA
}

\section{Introduction}

In principle, the combination of two different administration of anesthesia routes on the same patient improves effectiveness and reduces side effects (Stevens and Edwards, 1999) [B]: Spinal anesthesia provides fast and reliable segmental anesthesia with minimal risk for toxicity, while epidural anesthesia provides perioperative anesthesia (alone or in combination with general anesthesia), followed by excellent analgesia in the postoperative period (Cook, 2000;Rawal et al., 2000) [A]. Moreover, Combined Spinal Epidural (CSE) anesthesia reduces the potential for problems, such as the somewhat unpredictable level of blockade after spinal anesthesia, and the problems of missed segments, incomplete motor block, poor sacral spread and local anesthetic toxicity that can occur with epidural anesthesia (Cook, 2000) [A]. At the present time, CSE anesthesia is widely used in orthopedic, urologic and gynecologic surgery. Major CSE anesthesia benefits are the need for low doses of medications, low incidence of motor blockade, adequate sensory block, the ability to extend the area of blockade if the surgical field needs to be extended, and excellent analgesia (Rawal et al., 1997) [A]. However, use of CSE anesthesia or analgesia also introduces the potential for complications, such as technical failure, altered spread of epidural drugs in patients who also had a lumbar puncture, and altered spread of subarachnoid medications due to the effects of the epidural injection.

\section{History, anatomy, physiology and pharmacology}

\subsection{History}

CSE anesthesia was first described in 1937 by Dr A. Soresi, an Italian surgeon who injected medications in the subarachnoid and epidural space at the same time (Brill et al., 2003; Waegerle, 1999). The procedure, as described by Dr Soresi, was called "Episubdural Anesthesia" and involved use of the same fine needle for both the epidural and the subarachnoid injection. The needle was first advanced in the epidural space using the hanging drop technique, and $8 \mathrm{ml}$ of Novocain solution were injected. Then, the needle was advanced further, until it perforated the dura, and Novocain $2 \mathrm{ml}$ was injected in the subarachnoid space (Cook, 2000). This CSE anesthesia study included over 200 patients and 
analgesia lasted for 24 to 48 hours (Soresi, 1937). Dr Soresi recommended that no preliminary medication should be given to allay fear, anxiety, or restlessness, because he strongly believed that sedatives make spinal and episubdural anesthesia unsafe, and stated in his paper that "to attempt to allay fear, anxiety and restlessness with any drug is to court disaster" (Soresi, 1937) [C]. Of note, the technique described by Dr Soresi was carried out in an era when there were no IV infusions (caffeine-containing saline or dextrose solutions were administered by epidermoclysis instead) and no monitoring capabilities. "Episubdural anesthesia" did not involve placement of an epidural catheter, and Dr Soresi concluded his paper stating that "the hanging drop method renders episubdural anesthesia the safest procedure giving perfect surgical anesthesia, ideal relaxation, and eliminating practically all postoperative pain and distress" (Soresi, 1937) [C].

Dr I. Curelaru was the first to publish a study on CSE anesthesia in 1979 in the German medical journal "Praktische Anasthesie Wiederbelebung und Intensivtherapie" (Brill et al., 2003). This study included 150 patients, and CSE anesthesia was performed in two different interspaces: First, the epidural catheter was placed; then, a subarachnoid injection of Dixidextracaine was carried out two levels below the level of epidural catheter insertion. Dr Curelaru concluded that CSE anesthesia confers several advantages, including high quality conduction anesthesia that could be extended as needed, prolonged postoperative analgesia, analgesia covering a satisfactory number of dermatomes, minimal local anesthetic toxicity and absence of pulmonary complications (Curelaru, 1979) [B]. In addition, Dr Curelaru also discussed the drawbacks of the technique, including the need for two lumbar punctures, prolonged procedural time for the double procedure, and difficulty locating the subarachnoid space after inserting a catheter in the epidural space. The same year, Dr Brownridge proposed using CSE anesthesia for Cesarean section, and published his results, two years later in "Anaesthesia" (Brownridge, 1981;Carrie, 1988). Then, in 1982, Dr Coates et al. and Dr Mumtaz et al. described a technical innovation, introducing the "needle through needle" technique: (Coates, 1982;Mumtaz et al., 1982) local anesthetic was first injected in the subarachnoid space, and this injection was followed by placement of an epidural catheter. The use of a special CSE needle set was reported for the first time by Carrie and O'Sullivan in 1984, in the "European Journal of Anaesthesiology" (Carrie and O'Sullivan, 1984). The use of CSE anesthesia in obstetrics was first reported in 1989 at the "Queen Charlotte“ Hospital in London (Cook, 2000).

\subsection{Anatomy and physiology}

The epidural space, a potential space between the ligamentum flavum and the dura mater, surrounds the dural sac and contains fatty tissue and thin-walled blood vessels. The actual size of the epidural space varies: it is narrow in the thoracic region, due to spinal cord protuberances in the upper thoracic and bulges in the lower thoracic region, but it is wider below the level where the spinal cord ends (Katz and Renck, 1987). The distribution of epidural fat is also very important, because the course of the epidural catheter within the epidural space is influenced more by the epidural fat, rather than by connective tissue (Holmstrom et al., 1995). Because epidural fat is less viscous in children and more dense in adults, epidural catheters can be advanced more easily in children (Katz and Renck, 1987). Periduroscopic observations indicate that upon entering the epidural space, the epidural needle tip is in contact with the dura (Holmstrom et al., 1995). Therefore, variable further 
advancement of the spinal needle beyond the epidural needle tip is required in order to puncture the elastic dura when performing needle-through-needle CSE technique. The distance between the tip of the epidural needle and the posterior wall of the dural sac can be more than $10 \mathrm{~mm}$ in the midline; however, because the test injection used for identification of the epidural space may push the dura further back, the spinal needle used for CSE needs to be longer than conventional spinal needles (Rosenberg, 1998;Urmey, 2000). Consequently, CSE sets include extra long spinal needles, and it is important that CSE is performed caudad to the termination of the spinal cord at L2 (Katz and Renck, 1987).

\subsection{Pharmacology}

CSE anesthesia is an effective way to reduce drug doses required for anesthesia or analgesia, and the choice of medications is based on the concept of anti-nociceptive synergy: subarachnoid lipid soluble opioids (fentanyl or sufentanil) provide rapid (within 5-10 min) analgesia onset, improve surgical blockade quality (Rathmell et al., 2005) [A] and enhance the effect of small subarachnoid local anesthetic (bupivacaine) doses (Ben-David et al., 1997) [B], whereas subarachnoid morphine provides prolonged (lasting up to $24 \mathrm{hr}$ ) analgesia (Benzon HT et al., 2007). Furthermore, subarachnoid bupivacaine potentiates the effects of epidural bupivacaine (Stienstra et al., 1999) [B] and the anti-nociceptive effect of subarachnoid morphine (Akerman et al., 1988) [C].

The subarachnoid injection achieves rapid onset with minimal doses of local anesthetics and opioids, and the block can be prolonged as needed with low-doses of epidural medications. In addition, the sequential CSE method can be used to extend the dermatomal spread of the block with addition of minimal amounts of medications (Rawal, 2005;Rawal et al., 2000) [A]. The safety of CSE anesthesia is enhanced by the presence of the epidural catheter, which allows use of the lowest effective local anesthetic dose, thereby avoiding overshooting with regards to duration of spinal anesthesia. The rapid onset of anesthesia (from the spinal component) and the flexibility conferred by the epidural catheter make CSE anesthesia a safe and reliable anesthetic technique.

Reduction of drug doses with CSE anesthesia has made selective blockade possible, and many studies confirm that low-dose CSE anesthesia with local anesthetic and opioid, or lowdose epidural block alone, can provide effective analgesia with minimal motor and proprioceptive block. This selective blockade has made it possible for many patients to walk and bear weight normally while in labor and in the postoperative period. Therefore, CSE anesthesia is especially helpful for ambulatory surgical procedures of uncertain duration (Urmey, 2000), because the epidural catheter allows conversion from spinal to epidural anesthesia when it is necessary to extend the duration of the block. Of note, if the duration of surgery outlasts the initial subarachnoid block, it is necessary to inject at least 10 to $15 \mathrm{ml}$ of local anesthetic through the epidural catheter in order to maintain satisfactory anesthesia (Urmey, 2000).

CSE anesthesia often produces a more extensive block than expected, and the epidural dose needed to extend the block is often lower compared to doses needed with epidural anesthesia alone (Lew et al., 2004;Rawal et al., 1988) [A]. This observation has two possible explanations (Stienstra et al., 1996;Stienstra et al., 1999). First, the alleviation of subatmospheric pressure by the Tuohy needle before injection of the local anesthetic can reduce 
the volume of the subarachnoid space in the dural sac and extend the level of spinal anesthesia (Felsby and Juelsgaard, 1995). Second, diffusion of local anesthetic molecules from the epidural to the subarachnoid space through the dural hole is possible, due to dural sac compression after injection of local anesthetic in the epidural space (Blumgart et al., 1992).

A randomized controlled trial (RCT) by Tyagi et al studied the dose-sparing effect of epidural volume extension by comparing the ED50 of plain vs. hyperbaric bupivacaine with and without epidural volume extension in 88 male patients undergoing lower extremity orthopedic surgery. This study showed that, compared to hyperbaric bupivacaine, plain bupivacaine appears to be more effective, requiring a smaller dose and producing a higher sensory block with earlier onset. It also showed that epidural volume extension, when applied to subarachnoid hyperbaric bupivacaine, does not decrease the dose of subarachnoid medication and does not raise the level of block (Tyagi et al., 2008).

Spinal block during CSE may produce more extensive spread of local anesthetic in the subarachnoid space, compared to spinal block with the single shot technique in women having cesarean section. If that is true, then a smaller dose of local anesthetic will achieve a similar level of block when the CSE technique is used (Ithnin et al., 2006). However, data from two recent RCTs contradict these findings, and suggest that, when comparing singleshot spinal vs. CSE anesthesia, equal subarachnoid anesthetic doses produce comparable level of sensory blockade, and there is no need for adjustment of subarachnoid doses (Horstman et al., 2009; Lim et al., 2006). Similarly, a study by Kucukguclu evaluated the effect of epidural volume extension in women undergoing cesarean section under spinal anesthesia using the CSE technique with hyperbaric vs. plain $0.5 \%$ bupivacaine. This study did not show an effect of epidural volume extension on the spread of spinal anesthesia (Kucukguclu et al., 2008).

Recommended doses for standard CSE anesthesia in non-obstetric surgery are bupivacaine or levobupivacaine $0.5 \% 12.5$ to $20 \mathrm{mg}$, combined with preservative free morphine sulphate 100-300 $\mu \mathrm{g}$ for subarachnoid single shot injection (Rawal et al., 2000) [A]. Subarachnoid fentanyl (lipid-soluble, quick onset) and preservative-free morphine (water-soluble, slower onset, long duration) combined with small doses of subarachnoid bupivacaine can synergistically produce rapid and sustained analgesia (Gwirtz et al., 1999) [B]. Epidural topups require bupivacaine or levobupivacaine $0.5 \% 20-30 \mathrm{mg}$ combined with fentanyl $25 \mu \mathrm{g}$ or sufentanil 2.5-5 $\mu \mathrm{g}$ (Bouvet et al., 2011) [B].

CSE for cesarean section requires subarachnoid bupivacaine 0.5-0.75\%, 7.5-15 mg combined with opioids. Recommended opioid doses are fentanyl 20-25 $\mu \mathrm{g}$ and morphine 100-200 $\mu \mathrm{g}$ (somewhat lower compared to non obstetric patients). Epidural top-ups require bupivacaine or levobupivacaine 0.25 to $0.5 \% 10-40 \mathrm{mg}$ combined with fentanyl $25 \mu \mathrm{g}$ or sufentanil $2.5-5$ $\mu \mathrm{g}$ (Bouvet et al., 2011) [B]. Subarachnoid ropivacaine can also be used, but ropivacaine doses are 50\% higher, compared to bupivacaine or levobupivacaine (Coppejans and Vercauteren, 2006) [B].

Sequential CSE anesthesia for cesarean section requires subarachnoid hyperbaric bupivacaine $0.5 \% 5-7.5 \mathrm{mg}$ (the opioid dose is unchanged). Reduced subarachnoid hyperbaric bupivacaine doses result in adequate surgical analgesia with slower onset of maternal hypotension and decreased incidence of adverse effects. Epidural top-ups require 
bupivacaine $0.2-0.5 \% 10-50 \mathrm{mg}$ with fentanyl $20-25 \mu \mathrm{g}$ or sufentanil 5-10 $\mu \mathrm{g}$. Similarly, studies in non-obstetric surgery show that when CSE anesthesia is performed in the sitting position, epidural volume extension does not decrease the dose or raise the level of block produced by subarachnoid hyperbaric bupivacaine (Beale et al., 2005;Rawal, 2005;Tyagi et al., 2008) [A].

A RCT on patients undergoing major orthopedic surgery under spinal levobupivacaine/ sufentanil anesthesia, supplemented by subarachnoid $\mathrm{MgSO} 4(94.5 \mathrm{mg}, 6.3 \%)$ and epidural MgSO4 (2\%, $100 \mathrm{mg} / \mathrm{h})$ showed that subarachnoid and epidural magnesium significantly reduced patients' post-operative opioid analgesic requirements (Arcioni et al., 2007) [B].

\section{Indications, contraindications and clinical use of CSE Anesthesia}

Although CSE anesthesia was originally described for urologic surgery, indications for its use have expanded in recent years. CSE is now widely used in obstetrics (for labor analgesia and for cesarean sections), orthopedic surgery, trauma, abdominal, vascular and gynecologic surgery (Curelaru, 1979). CSE anesthesia allows the use of very low subarachnoid drug doses, due to the synergistic interaction between subarachnoid and epidural drugs. The CSE anesthesia is very appropriate for outpatient surgery, because the block wears off rapidly, so that patients ambulate earlier and can be discharged home sooner (Urmey, 2000;Urmey et al., 1995;Urmey et al., 1996) [B]. Contraindications to CSE anesthesia are the same as for any neuraxial block.

\begin{tabular}{ll}
\hline Surgery type & Surgical procedure \\
\hline Obstetrics & Labor analgesia, Cesarean Section \\
Gynecology & Hysterectomy \\
Orthopedics & Hip and knee surgery \\
Urology & Prostatectomy, cystectomy \\
Abdominal surgery & Colorectal, renal transplantation \\
Vascular surgery & Open surgical repair of infrarenal abdominal aortic \\
& aneurysm \\
Ambulatory surgery & Reconstructive surgery of lower extremities \\
Pediatric surgery & Knee arthroscopy \\
\hline
\end{tabular}

Table 1. Use of CSE anesthesia in surgical practice

\section{CSE Techniques}

\subsection{Needle-through-needle technique}

The first "spinal-needle-through-epidural needle" technique was described by Coates (Rosenberg, 1998). After the epidural space is identified using an epidural needle, the epidural needle serves as introducer, and a fine spinal needle is advanced through the epidural needle, beyond its tip, until it punctures the dura. Medications are first injected in the subarachnoid space, and then the epidural catheter is inserted. Disadvantages of this 
technique are the possibility for advancing the epidural catheter into the subarachnoid space, and the possibility for needle damage from friction between the needles. Although it is possible to combine a plain Tuohy needle with a longer, thinner spinal needle for performing the procedure, special commercial "all in one" kits have become available. Long thin needles make it more difficult to feel perforation of the dura; therefore, the "hanging drop" technique is recommended to identify the spinal space after dura perforation (Kopacz and Bainton, 1996) [C].The "Hanging drop" technique consists of placing one drop of normal saline in the hub of spinal needle. This "hanging drop" will fall down from the hub of the needle when the spinal needle reaches the subarachnoid space.

"Backeye" is the hole constructed in the curvature of the epidural needle tip, so that the spinal needle can advance along a straight route into the epidural space. This design allows smooth advancement of the spinal needle, without friction between the epidural catheter and the spinal needle, and may reduce the risk of epidural catheter migration through holes opened by the spinal needle (Hanaoka K, 1986;:iu and McDonald, 2001) [B].

The Espocan CSE set (Braun) contains an epidural needle constructed with a plastic sleeve inside. This sleeve leads the spinal needle and separates it from the epidural catheter (Browne et al., 2005). Information on this set is available online. Another commercial product, the Epistar needle, has two channels: one for the epidural catheter and one for the spinal needle. The Epistar needle confers the advantage that spinal anesthesia is performed after the epidural catheter has been inserted and a test dose has been given to confirm proper epidural catheter placement. (Stamenkovic et al., 2009) [B]. Information on the Epistar CSE set is also available online.

\subsection{Separate needles}

In this technique, the two components of CSE (spinal and epidural injection) are performed using separate needles, in the same or at different inter-vertebral spaces, in either order (Cook, 2000).

Performing both the epidural and spinal injection at the same interspace requires infiltration with local anesthetic only once. When using this technique, the epidural needle is placed first, to serve as introducer for the spinal needle at the same interspace. Then, after the epidural catheter is advanced, the spinal needle is advanced in order to puncture the dura and allow the subarachnoid injection (Turner and Reifenberg, 1995) [B]. When using this technique, epidural catheter damage caused with spinal needle during dural puncture is a possible complication. A modification of this technique, proposed by Cook, suggested that the spinal needle be placed as low as possible in the interspace, whereas the epidural catheter be placed cephalad, and then subarachnoid injection be performed (Cook, 2004) [B].

The technique using two different interspaces confers the advantage that it allows epidural catheter placement in the thoracic or the lumbar area, depending on the location of the pain, while the subarachnoid injection is still done in the lumbar area (Stamenkovic et al., 2008) [B]. In addition, this technique allows the use of an epidural test dose to confirm appropriate placement of the epidural catheter before the spinal injection, and avoids potential puncture of the epidural catheter by the spinal needle. However, despite these presumed advantages, in the absence of robust evidence, expert opinion suggests that, compared to the separate interspaces technique, the "needle-through-needle" technique causes "considerably less 
discomfort, trauma and morbidity from inter-spinous space penetration including backache, epidural venous puncture, hematoma, infection and technical difficulties" (Rawal et al., 1997).

\subsection{Special single CSE needles}

The Eldor needle technique is a slightly different technique that was introduced in 1990, and uses a specialized needle for CSE. The Eldor needle is both spinal and epidural needle, combining an 18G epidural needle with a 20G spinal conduit, and the epidural catheter can be introduced before the spinal injection. An image of the needle is available online at the company website. Use of the Eldor needle reduces the risk of accidental subarachnoid placement of the epidural catheter, and avoids friction of the needles and post-dural puncture headaches. The Eldor needle is used as follows: First, the spinal needle is introduced into the guide needle. Then, the Eldor needle is placed in the selected intervertebral space, using the "loss of resistance" technique to locate the epidural space. After reaching the epidural space, the epidural catheter is inserted first, and then the spinal needle is advanced until it perforates the dura. Following the subarachnoid injection, the spinal needle is removed, and then the Eldor needle is also removed.

The Coombs epidural -spinal needle is a newer multi-lumen device (Eldor, 1997) that has two different channels, with the spinal channel being underneath the epidural channel. However, despite their advantages, Eldor needles and Coombs needles have not gained widespread popularity because they are uncomfortably large (Rosenberg, 1998) [B].

A RCT comparing a CSE set with an interlocking device between the spinal and epidural needle vs. a CSE set with a "backeye" at the epidural needle curve for passage of the spinal needle vs. the double-segment technique, showed that use of CSE sets does not save time compared with the double segment technique (Puolakka et al., 2001). Moreover damaged spinal needle tips were noted relatively often with the interlocking CSE set [B].

\subsection{Dual catheter technique}

The dual catheter technique involves the insertion of two catheters, one in the epidural space and one in the subarachnoid space on the same patient. Having both an epidural and a subarachnoid catheter confers certain advantages, in that both spinal anesthesia and epidural analgesia can be extended or prolonged, as needed for surgery and postoperative analgesia. However, having two similar catheters on the same patient introduces the potential for serious errors, mainly the inadvertent subarachnoid injection of medications in doses intended for epidural use. Clearly, such errors could be life-threatening if not detected early. At the present time due to concerns about the risk of inadvertent epidural injection of local anesthetic through the subarachnoid, rather than through the epidural catheter, the dual catheter technique is rarely used (Dahl et al., 1990; Vercauteren et al., 1993).

\section{Comparison of CSE vs. spinal or epidural anesthesia or analgesia}

Compared to conventional neuraxial (spinal or epidural) anesthesia, CSE anesthesia is technically more demanding, but can confer certain advantages. Data on proven or potential advantages of CSE anesthesia compared to epidural or spinal anesthesia are as follows: 
A RCT on 75 patients undergoing major orthopedic surgery compared CSE vs. spinal vs. epidural anesthesia, and showed that spinal and CSE provided effective and reliable block with muscle relaxation and good surgical conditions rapidly, and both techniques were superior to epidural anesthesia (Holmstrom et al., 1993) [B].

A retrospective chart review in a community hospital assessed the safety and efficacy of 6,002 CSE analgesia/anesthesia blocks, and compared these results with reported complications and failure rates for spinal and epidural anesthesia. This study showed that, compared to epidural anesthesia, CSE anesthesia had lower failure rates for labor analgesia and comparable or lower failure rates for surgical anesthesia. There were no cases of apnea among parturients who received 4,164 CSE blocks with subarachnoid sufentanil (10,15, or $20 \mu \mathrm{g})$ for labor analgesia. However, the need for intravenous medications to treat CSE sideeffects increased with increasing subarachnoid sufentanil doses: medications were needed in $1.1 \%$ of patients who received sufentanil $10 \mu \mathrm{g}, 4.6 \%$ of patients who received sufentanil $15 \mu \mathrm{g}$, and $5.5 \%$ of patients who received sufentanil $20 \mu \mathrm{g}$. The study concluded that CSE was safe and efficacious for labor and surgical anesthesia (Albright and Forster, 1999) [B].

Use of CSE anesthesia or epidural improved postoperative recovery in patients undergoing retro-pubic prostatectomy, and resulted in one day hospitalization with minimal postoperative morbidity and high patient satisfaction (Kirsh et al., 2000) [B].

Furthermore, CSE anesthesia was performed in the right lateral position using a doublespace technique in 50 patients undergoing renal transplantation. Neuraxial blockade was satisfactory in all but four patients who required supplemental general anesthesia for prolonged surgery. This study concluded that CSE anesthesia was very useful, combining the reliability of spinal block with the versatility of epidural block for renal transplantation (Bhosale and Shah, 2008) [B]. CSE anesthesia can also be safely used for living donor nephrectomy, resulting in good surgeon satisfaction and patient comfort, and could be the method of choice for patients anxious about general anesthesia (Haberal et al., 2002) [C].

Postoperative pain after abdominal surgery (especially surgery involving more than one organ) is a challenge in institutions where expensive delivery systems, such as infusion pumps for continuous epidural analgesia, are not available. Compared to epidural analgesia, CSE analgesia using preoperative subarachnoid morphine, fentanyl and bupivacaine resulted in better postoperative control of pain with cough, fewer additional analgesia requests in the first 24 hours postoperatively, and reduced amounts of supplemental intra-operative IV fentanyl and epidural bupivacaine (Stamenkovic et al., 2008) [B].

\section{CSE anesthesia in special populations}

\subsection{Patients with significant cardiac or pulmonary disease}

CSE anesthesia alone, without general anesthesia, intubation or mechanical ventilation, can be a good anesthetic option in patients with severe chronic obstructive pulmonary disease (COPD) who undergo open repair of infra-renal abdominal aortic aneurysm (AAA), if general anesthesia would pose too high a risk and endovascular repair is not feasible (Berardi et al., 2010) [C]. Berardi et al, presented series of seven high-risk patients ages 70 to 87 undergoing open AAA repair. Average AAA diameter was $7 \mathrm{~cm}$ (range 6-12.2). The 
anesthetic plan included spinal anesthesia at L2-3 (levobupivacaine plus fentanyl), combined with epidural anesthesia at T7-8 (levobupivacaine). All patients tolerated the procedure well, without morbidity or mortality for 12 months after surgery.

Another case series described three patients undergoing open infrarenal AAA repair under CSE anesthesia, and concluded that CSE anesthesia is a "viable" anesthetic option in patients with severe COPD, because it can preserve spontaneous breathing and provide respiratory benefits over general anesthesia (Flores et al., 2002) [C].

Use of CSE anesthesia has also been reported in patients with severe COPD undergoing abdominoplasty, sigmoid-colectomy, right hemicolectomy and cholecystectomy (Kodeih et al., 2009;Moiniche et al., 1994;Morton and Bowler, 2001;van Zundert et al., 2007).

The safety of low-dose sequential CSE analgesia in women with unrepaired cyanotic heart disease who required analgesia for labor has recently been reported (Arendt et al., 2011) [C]. In addition, one case report described successful management of a patient with untreated ventricular septal defect and pulmonary atresia who had hysterectomy under CSE anesthesia (Agarwal et al., 2010).

\subsection{CSE anesthesia in the elderly}

Several studies have investigated the use of CSE anesthesia in geriatric patients. One study from Japan on 17 patients older than 80 years who underwent lower extremity orthopedic surgery showed that, compared to spinal or epidural anesthesia alone, CSE anesthesia was preferred, providing rapid onset, reliable spinal block and high quality intraoperative and postoperative analgesia (Wakamatsu et al., 1991). Another study by Tahtaci et al. on 19 elderly patients (mean age 75.8 years) showed that CSE anesthesia provides "sufficient anaesthesia with fewer complications" than spinal anesthesia (Tahtaci and Neyal, 2002) [C].

Similarly, a case report by Morton described the successful use of CSE anesthesia for sigmoid colectomy in an 82-year-old woman with congestive heart disease, COPD, osteoporosis and severe kyphosis (Morton and Bowler, 2001).

\subsection{CSE anesthesia in obstetrics}

Because traditional epidural techniques have been associated with prolonged labor, increased need for oxytocin augmentation, and increased incidence of instrumental vaginal delivery, CSE was introduced in obstetrics as an attempt to reduce these adverse effects. CSE is currently very popular in obstetric anesthesia and analgesia (Blanshard and Cook, 2004), because it is believed to improve maternal mobility during labor and, compared to traditional epidural analgesia, provide more rapid onset of analgesia and higher maternal satisfaction. In addition, CSE allows prolongation of epidural analgesia or conversion to CSE anesthesia, if cesarean section is needed.

A retrospective study on 77 pre-eclamptic parturients (26 women with severe pre-eclampsia, 51 with mild pre-eclampsia) undergoing Cesarean section, showed that CSE anesthesia is safe in women with pre-eclampsia and severe pre-eclampsia (Van, V et al., 2004) [B].

In addition, CSE can be a good option in pregnant women with a variety of serious medical conditions: CSE anesthesia or analgesia was successfully used in a parturient with severe 
myasthenia gravis (D'Angelo and Gerancher, 1998), idiopathic hypertrophic sub-aortic stenosis (Ho et al., 1997), mitral stenosis (Ngan Kee et al., 1999), dilated cardiomyopathy (Shnaider et al., 2001), Guillain-Barre syndrome (Vassiliev et al., 2001), Laron syndrome (Bhatia and Cockerham, 2011), tetralogy of Fallot (Arendt et al., 2011), Liddle's syndrome (Hayes et al., 2011), Wegener's granulomatosis with subglottic stenosis (Engel et al., 2011).

Another prospective study on 2183 laboring women, showed that labor progress and outcome are similar among women receiving either CSE or epidural analgesia and that CSE analgesia is not associated with increased frequency of anesthetic complications (Norris et al., 2001) [B].

A Cochrane review analyzed nineteen trials (2658 women) evaluating CSE vs. epidural analgesia in labor (Simmons et al., 2007) [A]. Twenty-six outcomes in two sets of comparisons involving CSE vs. traditional epidurals and CSE vs. low-dose epidural techniques were analyzed. When comparing CSE vs. traditional epidural analgesia, CSE was better with regards to need for rescue analgesia and urinary retention, but was associated with more pruritus. When comparing CSE vs. low-dose epidurals, CSE patients experienced faster onset of effective analgesia, but more pruritus. In addition, CSE was associated with lower (not clinically significant) umbilical arterial $\mathrm{pH}$, but there were no differences with regards to maternal satisfaction, mobilization during labor, maternal hypotension, modes of birth, incidence of post-dural puncture headache or need for epidural blood patch. It was not possible to draw any conclusions regarding maternal respiratory depression, maternal sedation and need for augmentation of labor, and there was no difference in obstetric or neonatal outcomes. Based on these results, the authors concluded that available evidence cannot support a specific recommendation for CSE vs. epidurals in labor. However, the significantly higher incidence of urinary retention and rescue interventions needed with traditional epidurals would favor the use of low-dose epidurals. Currently available data cannot support any conclusions regarding rare complications such as nerve injury or meningitis.

\subsection{CSE anesthesia in pediatrics}

In order to evaluate the safety of CSE anesthesia in neonates and infants undergoing elective major abdominal surgery, spinal anesthesia was performed in 28 neonates and infants using isobaric bupivacaine $0.5 \%, 1 \mathrm{mg} / \mathrm{kg}$, followed by placement of a caudal epidural catheter that was advanced to reach thoracic spinal segments (Somri et al., 2007). This study showed that CSE was well tolerated, and the authors concluded that "CSE anesthesia could be considered as an effective anesthetic technique for elective major upper abdominal surgery in awake or sedated neonates and infants, and could be used cautiously by a pediatric anesthesiologist as an alternate to general anesthesia in high-risk neonates and infants undergoing upper gastrointestinal surgery". However, four patients required conversion from CSE anesthesia to general anesthesia, whereas twenty patients required midazolam for sedation, oxygen supplementation and transient manual ventilation.

One more study included 19 infants undergoing major abdominal surgery (including small bowel resections and genitourinary procedures) under CSE anesthesia with spinal tetracaine and epidural bupivacaine. Then, epidural analgesia was successfully used for postoperative pain (Williams et al., 1997). 
Fifty infants undergoing elective gastrointestinal surgery were included in a RCT designed to compare CSE vs. general anesthesia with regards to cardio-respiratory adverse events during an 8-day follow-up period in the intensive care unit (Somri et al., 2011). This study showed that, compared to patients receiving general anesthesia, patients who received CSE anesthesia had fewer adverse respiratory and cardiovascular events [B]. Furthermore, adverse cardiovascular events were more resistant to treatment in the general anesthesia group.

In conclusion, limited data suggest that CSE can be very useful in certain pediatric surgery patients. However, more research is needed to fully evaluate the role of CSE in pediatric surgery.

\section{Concerns, technical failures and potential complications of CSE anesthesia}

Potential concerns related to the clinical use of CSE include failure of the spinal and/or epidural component, spinal migration of the epidural catheter, the possibility of subdural block and the potential for subarachnoid administration of medications intended for epidural use. Other potential problems include failure of the test dose, post-dural puncture headache, and very rare catastrophic complications, including CNS injuries or CNS infection.

\subsection{Epidural catheter migration into the subarachnoid space}

The possibility that the epidural catheter could migrate into the subarachnoid space through the hole created on the dura by the spinal needle is subject to controversy. Published data suggest that rotation of the epidural needle is unnecessary, because there is no risk for epidural dislodgement into the subarachnoid space, if the dural puncture is performed with a 26-gauge spinal needle (Rawal et al., 1988). However, it is still possible that epidurally administered medications could enter the subarachnoid space through the hole in dura, especially if "wet tap" occurred (Bernards et al., 1994).

\subsection{Failure of the spinal or epidural component of CSE}

Some data suggest that failure rate of the spinal component of CSE (approximately 5\%) is higher compared to spinal anesthesia alone (Cook, 2000). Indeed, there are several reasons why the spinal component could fail more frequently during CSE. First, the small size of the spinal needle can contribute to failure, because the thinner, smaller spinal needles used for CSE result in slower return of cerebrospinal fluid (CSF) and higher resistance to injection (Liu and McDonald, 2001). Second, movement of the spinal needle beyond the epidural needle can be problematic when the tiny spinal needle loses support. Third, deviation of the spinal needle away from midline is a possibility that could compromise success of the subarachnoid injection (Rawal et al., 1997). In addition, if water is used for the "loss of resistance" technique during epidural placement, water return through the hub of the spinal needle can be wrongly interpreted as CSF (Liu and McDonald, 2001).

The epidural component of CSE can also fail: If the subarachnoid injection is performed before the epidural block, use of a test dose to confirm appropriate epidural catheter 
placement is no longer possible. The incidence of failure of the epidural CSE component is unknown (Liu and McDonald, 2001), but, unfortunately epidural block failure can only be recognized late, after surgery has started.

\subsection{Paresthesias}

During CSE, paresthesias occur at the time of spinal needle advancement in $2.6 \%$ to $10 \%$ of cases, but the incidence has been reported to be up to $29 \%$ when long spinal needles are used (Casati et al., 1998;Herbstman et al., 1998;Hoffmann et al., 1997). Long needles, particularly when the length beyond the tip of the epidural needle was longer than $12 \mathrm{~mm}$, caused more transitional paresthesia during needle insertion, but no residual effects (Herbstman et al., 1998). One case of prolonged left lower limb paresis has been reported following CSE anesthesia for obstetric surgery. Magnetic resonance imaging (MRI) in this case showed marked swelling of the lower end of the spinal cord suggesting traumatic damage of the cord by the spinal needle (Rajakulendran et al., 1999).

\subsection{Cauda equina syndrome}

Two cases of cauda equina syndrome have been reported after CSE (Kubina et al., 1997). In another case, the patient reported buttock numbness with an area of hypesthesia in the distribution of the lower sacral nerves, but there were no significant imaging findings, and sensation fully recovered after 7 months (Paech, 1997). The etiology of neurologic deficits in these cases remains unknown, but drug-induced neurotoxicity could be a plausible explanation.

\subsection{Meningitis}

The risk of meningitis after CSE is unknown, but several cases of aseptic or bacterial post CSE meningitis have been reported with the needle-through-needle or the two space technique (Aldebert and Sleth, 1996;Harding et al., 1994;Kasai et al., 2003;Sandkovsky et al., 2009; Vasquez et al., 2002). Meticulous aseptic technique is important during CSE, and special care is needed to maintain sterility while preparing drug solutions (Rawal et al., 2000).

\subsection{Epidural abscess}

Although epidural abscess is rare, two case reports have described epidural abscess formation after CSE (Dysart and Balakrishnan, 1997;Schroter et al., 1997). One of these two patients was managed conservatively (Dysart and Balakrishnan, 1997), while the other patient required hemi-laminectomy and surgical drainage of the abscess (Schroter et al., 1997).

\subsection{Adhesive arachnoiditis}

Recently, Hirai et al published an extremely rare case of paraplegia due to adhesive arachnoiditis with extensive syringomyelia (ES) and a giant anterior arachnoid spinal cyst (AASC) after CSE anesthesia for obstetric surgery in a young patient (Hirai et al., 2011). Spinal cord MRI showed spinal cord compression at T1-6 and an adhesive lesion at T7. 
Posterior laminectomy at T6-7 and adhesiolysis of the arachnoid adhesion at T7 were performed, followed by cyst-peritoneal shunt into the AASC.

\subsection{Subdural hematoma}

One case of subdural hematoma has been reported after needle through needle CSE in an obstetric patient with mild thrombocytopenia (Bougher and Ramage, 1995).

\section{Conclusion}

CSE is the combination of spinal and epidural anesthesia and analgesia on the same patient. Compared to conventional spinal or epidural anesthesia, CSE is a newer technique that was developed in an attempt to combine the advantages of spinal and epidural anesthesia/analgesia, while minimizing their disadvantages. CSE is currently popular and it is used in a wide variety of clinical settings, including general surgery, vascular surgery, urology, orthopedic surgery, obstetrics and gynecology and pediatric surgery. CSE seems to be particularly useful in ambulatory surgery, because it facilitates early patient ambulation and discharge to home. In addition, CSE probably has a role in patients with significant comorbidities, who need to undergo surgery and are considered at high risk for general anesthesia.

\section{Clinical pearls}

CSE consists of a single subarachnoid injection combined with insertion of an epidural catheter for intermittent or continuous epidural administration of medications

CSE is an effective way to reduce drug doses required for anesthesia and analgesia

CSE is safe and efficacious for labor analgesia and surgical anesthesia, particularly for ambulatory surgery

CSE anesthesia alone, without general anesthesia, can be a good anesthetic option in patients with severe chronic pulmonary disease

Low-dose sequential CSE anesthesia has been successfully used in adults with unrepaired cyanotic heart disease or other significant cardiac co-morbidities

Limited data suggest that CSE can be very useful in certain pediatric surgery patients

\section{References}

Agarwal, A., R. Garg, A. Joshi, and S. Verma, 2010, Combined spinal epidural anesthesia with epidural volume extension technique for hysterectomy in patient with unpalliated cyanotic heart disease--a case-report: Acta Anaesthesiol.Belg., v. 61, no. 3, p. 159-161.

Akerman, B., E. Arwestrom, and C. Post, 1988, Local anesthetics potentiate spinal morphine antinociception: Anesth.Analg., v. 67, no. 10, p. 943-948. 
Albright, G. A., and R. M. Forster, 1999, The safety and efficacy of combined spinal and epidural analgesia/anesthesia (6,002 blocks) in a community hospital: Reg Anesth.Pain Med., v. 24, no. 2, p. 117-125.

Aldebert, S., and J. C. Sleth, 1996, [Bacterial meningitis after combined spinal and epidural anesthesia in obstetrics]: Ann.Fr.Anesth.Reanim., v. 15, no. 5, p. 687-688.

Arcioni, R. et al., 2007, Combined intrathecal and epidural magnesium sulfate supplementation of spinal anesthesia to reduce post-operative analgesic requirements: a prospective, randomized, double-blind, controlled trial in patients undergoing major orthopedic surgery: Acta Anaesthesiol.Scand., v. 51, no. 4, p. 482-489.

Arendt, K. W., S. M. Fernandes, P. Khairy, C. A. Warnes, C. H. Rose, M. J. Landzberg, P. A. Craigo, and J. R. Hebl, 2011, A case series of the anesthetic management of parturients with surgically repaired tetralogy of Fallot: Anesth.Analg., v. 113, no. 2, p. 307-317.

Beale, N., B. Evans, F. Plaat, M. O. Columb, G. Lyons, and G. M. Stocks, 2005, Effect of epidural volume extension on dose requirement of intrathecal hyperbaric bupivacaine at Caesarean section: Br.J.Anaesth., v. 95, no. 4, p. 500-503.

Ben-David, B., E. Solomon, H. Levin, H. Admoni, and Z. Goldik, 1997, Intrathecal fentanyl with small-dose dilute bupivacaine: better anesthesia without prolonging recovery: Anesth.Analg., v. 85, no. 3, p. 560-565.

Benzon HT, Candido KD, and Wong CA, 2007, Postoperative neuraxial analgesia, in Wong CA ed., Spinal and Epidural Anesthesia: New York, McGraw-Hill Companies Inc, p. 325-347.

Berardi, G. et al., 2010, Combined spinal and epidural anesthesia for open abdominal aortic aneurysm surgery in vigil patients with severe chronic obstructive pulmonary disease ineligible for endovascular aneurysm repair. Analysis of results and description of the technique: Int.Angiol., v. 29, no. 3, p. 278-283.

Bernards, C. M., D. J. Kopacz, and M. Z. Michel, 1994, Effect of needle puncture on morphine and lidocaine flux through the spinal meninges of the monkey in vitro. Implications for combined spinal-epidural anesthesia: Anesthesiology, v. 80, no. 4, p. 853-858.

Bhatia, K., and R. Cockerham, 2011, Anaesthetic management of a parturient with Laron syndrome: Int.J.Obstet.Anesth..

Bhosale, G., and V. Shah, 2008, Combined spinal-epidural anesthesia for renal transplantation: Transplant.Proc., v. 40, no. 4, p. 1122-1124.

Blanshard, H. J., and T. M. Cook, 2004, Use of combined spinal-epidural by obstetric anaesthetists: Anaesthesia, v. 59, no. 9, p. 922-923.

Blumgart, C. H., D. Ryall, B. Dennison, and L. M. Thompson-Hill, 1992, Mechanism of extension of spinal anaesthesia by extradural injection of local anaesthetic: Br.J.Anaesth., v. 69, no. 5, p. 457-460.

Bougher, R. J., and D. Ramage, 1995, Spinal subdural haematoma following combined spinal-epidural anaesthesia: Anaesth.Intensive Care, v. 23, no. 1, p. 111-113.

Bouvet, L., X. Da-Col, D. Chassard, F. Dalery, L. Ruynat, B. Allaouchiche, E. Dantony, and E. Boselli, 2011, ED and ED of intrathecal levobupivacaine with opioids for Caesarean delivery: Br.J.Anaesth., v. 106, no. 2, p. 215-220. 
Brill, S., G. M. Gurman, and A. Fisher, 2003, A history of neuraxial administration of local analgesics and opioids: Eur.J.Anaesthesiol., v. 20, no. 9, p. 682-689.

Browne, I. M., D. J. Birnbach, D. J. Stein, D. A. O'Gorman, and M. Kuroda, 2005, A comparison of Espocan and Tuohy needles for the combined spinal-epidural technique for labor analgesia: Anesth.Analg., v. 101, no. 2, p. 535-40, table.

Brownridge, P., 1981, Epidural and subarachnoid analgesia for elective caesarean section: Anaesthesia, v. 36, no. 1, p. 70.

Carrie, L. E., 1988, Epidural versus combined spinal epidural block for caesarean section: Acta Anaesthesiol.Scand., v. 32, no. 7, p. 595-596.

Carrie, L. E., and G. O'Sullivan, 1984, Subarachnoid bupivacaine $0.5 \%$ for caesarean section: Eur.J.Anaesthesiol., v. 1, no. 3, p. 275-283.

Casati, A., A. D'Ambrosio, N. P. De, G. Fanelli, V. Tagariello, and F. Tarantino, 1998, A clinical comparison between needle-through-needle and double-segment techniques for combined spinal and epidural anesthesia: Reg Anesth.Pain Med., v. 23, no. 4, p. 390-394.

Coates, M. B., 1982, Combined subarachnoid and epidural techniques: Anaesthesia, v. 37, no. 1 , p. 89-90.

Cook, T. M., 2000, Combined spinal-epidural techniques: Anaesthesia, v. 55, no. 1, p. 42-64.

Cook, T. M., 2004, 201 combined spinal-epidurals for anaesthesia using a separate needle technique: Eur.J.Anaesthesiol., v. 21, no. 9, p. 679-683.

Coppejans, H. C., and M. P. Vercauteren, 2006, Low-dose combined spinal-epidural anesthesia for cesarean delivery: a comparison of three plain local anesthetics: Acta Anaesthesiol.Belg., v. 57, no. 1, p. 39-43.

Curelaru, I., 1979, Long duration subarachnoid anaesthesia with continuous epidural block: Prakt.Anaesth., v. 14, no. 1, p. 71-78.

D'Angelo, R., and J. C. Gerancher, 1998, Combined spinal and epidural analgesia in a parturient with severe myasthenia gravis: Reg Anesth.Pain Med., v. 23, no. 2, p. 201-203.

Dahl, J. B., J. Rosenberg, W. E. Dirkes, T. Mogensen, and H. Kehlet, 1990, Prevention of postoperative pain by balanced analgesia: Br.J.Anaesth., v. 64, no. 4, p. 518-520.

Dysart, R. H., and V. Balakrishnan, 1997, Conservative management of extradural abscess complicating spinal-extradural anaesthesia for caesarean section: Br.J.Anaesth., v. 78, no. 5, p. 591-593.

Eldor, J., 1997, The evolution of combined spinal-epidural anesthesia needles: Reg Anesth., v. 22, no. 3, p. 294-296.

Engel, N. M., H. F. Gramke, L. Peeters, and M. A. Marcus, 2011, Combined spinal-epidural anaesthesia for a woman with Wegener's granulomatosis with subglottic stenosis: Int.J.Obstet.Anesth., v. 20, no. 1, p. 94-95.

Felsby, S., and P. Juelsgaard, 1995, Combined spinal and epidural anesthesia: Anesth.Analg., v. 80 , no. 4 , p. $821-826$.

Flores, J. A., T. Nishibe, M. Koyama, T. Imai, F. Kudo, K. Miyazaki, and K. Yasuda, 2002, Combined spinal and epidural anesthesia for abdominal aortic aneurysm surgery in patients with severe chronic pulmonary obstructive disease: Int.Angiol., v. 21, no. 3, p. 218-221. 
Gwirtz, K. H., J. V. Young, R. S. Byers, C. Alley, K. Levin, S. G. Walker, and R. K. Stoelting, 1999, The safety and efficacy of intrathecal opioid analgesia for acute postoperative pain: seven years' experience with 5969 surgical patients at Indiana University Hospital: Anesth.Analg., v. 88, no. 3, p. 599-604.

Haberal, M., R. Emiroglu, G. Arslan, E. Apek, H. Karakayali, and N. Bilgin, 2002, Livingdonor nephrectomy under combined spinal-epidural anesthesia: Transplant.Proc., v. 34 , no. 6 , p. $2448-2449$.

Hanaoka K. Experience in the use of Hanaoka's needles for spinal-continuous epidural anaesthesia (500 cases). 7th Asian Australian Congess of Anaesthesiologists Abstracts , 161-162. 1986.

Ref Type: Abstract

Harding, S. A., R. E. Collis, and B. M. Morgan, 1994, Meningitis after combined spinalextradural anaesthesia in obstetrics: Br.J.Anaesth., v. 73, no. 4, p. 545-547.

Hayes, N. E., A. Aslani, and C. L. McCaul, 2011, Anaesthetic management of a patient with Liddle's syndrome for emergency caesarean hysterectomy: Int.J.Obstet.Anesth., v. 20, no. 2, p. 178-180.

Herbstman, C. H., J. B. Jaffee, K. J. Tuman, and L. M. Newman, 1998, An in vivo evaluation of four spinal needles used for the combined spinal-epidural technique: Anesth.Analg., v. 86, no. 3, p. 520-522.

Hirai, T., T. Kato, S. Kawabata, M. Enomoto, S. Tomizawa, T. Yoshii, K. Sakaki, K. Shinomiya, and A. Okawa, 2011, Adhesive Arachnoiditis with Extensive Syringomyelia and Giant Arachnoid Cyst Following Spinal and Epidural Anesthesia: A Case Report: Spine (Phila Pa 1976.).

Ho, K. M., W. D. Ngan Kee, and M. C. Poon, 1997, Combined spinal and epidural anesthesia in a parturient with idiopathic hypertrophic subaortic stenosis: Anesthesiology, v. 87, no. 1, p. 168-169.

Hoffmann, V. L., M. P. Vercauteren, P. W. Buczkowski, and G. L. Vanspringel, 1997, A new combined spinal-epidural apparatus: measurement of the distance to the epidural and subarachnoid spaces: Anaesthesia, v. 52, no. 4, p. 350-355.

Holmstrom, B., K. Laugaland, N. Rawal, and S. Hallberg, 1993, Combined spinal epidural block versus spinal and epidural block for orthopaedic surgery: Can.J.Anaesth., v. 40, no. 7, p. 601-606.

Holmstrom, B., N. Rawal, K. Axelsson, and P. A. Nydahl, 1995, Risk of catheter migration during combined spinal epidural block: percutaneous epiduroscopy study: Anesth.Analg., v. 80, no. 4, p. 747-753.

Horstman, D. J., E. T. Riley, and B. Carvalho, 2009, A randomized trial of maximum cephalad sensory blockade with single-shot spinal compared with combined spinal-epidural techniques for cesarean delivery: Anesth.Analg., v. 108, no. 1, p. 240-245.

Ithnin, F., Y. Lim, A. T. Sia, and C. E. Ocampo, 2006, Combined spinal epidural causes higher level of block than equivalent single-shot spinal anesthesia in elective cesarean patients: Anesth.Analg., v. 102, no. 2, p. 577-580.

Kasai, T., K. Yaegashi, M. Hirose, T. Fujita, and Y. Tanaka, 2003, Aseptic meningitis during combined continuous spinal and epidural analgesia: Acta Anaesthesiol.Scand., v. 47 , no. 6, p. 775-776. 
Katz, J., and H. Renck, 1987, Handbook of Thoraco-abdominal Nerve Block Hertfordshire, Prentice Hall PTR.

Kirsh, E. J., E. M. Worwag, M. Sinner, and G. W. Chodak, 2000, Using outcome data and patient satisfaction surveys to develop policies regarding minimum length of hospitalization after radical prostatectomy: Urology, v. 56, no. 1, p. 101-106.

Kodeih, M. G., A. A. Al-Alami, B. S. Atiyeh, and G. E. Kanazi, 2009, Combined spinal epidural anesthesia in an asthmatic patient undergoing abdominoplasty: Plast.Reconstr.Surg., v. 123, no. 3, p. 118e-120e.

Kopacz, D. J., and B. G. Bainton, 1996, Combined spinal epidural anesthesia: a new "hanging drop": Anesth.Analg., v. 82, no. 2, p. 433-434.

Kubina, P., A. Gupta, A. Oscarsson, K. Axelsson, and M. Bengtsson, 1997, Two cases of cauda equina syndrome following spinal-epidural anesthesia: Reg Anesth., v. 22, no. 5 , p. 447-450.

Kucukguclu, S., H. Unlugenc, F. Gunenc, B. Kuvaki, N. Gokmen, S. Gunasti, S. Guclu, F. Yilmaz, and G. Isik, 2008, The influence of epidural volume extension on spinal block with hyperbaric or plain bupivacaine for Caesarean delivery: Eur.J.Anaesthesiol., v. 25, no. 4, p. 307-313.

Lew, E., S. W. Yeo, and E. Thomas, 2004, Combined spinal-epidural anesthesia using epidural volume extension leads to faster motor recovery after elective cesarean delivery: a prospective, randomized, double-blind study: Anesth.Analg., v. 98, no. 3, p. 810-814.

Lim, Y., W. Teoh, and A. T. Sia, 2006, Combined spinal epidural does not cause a higher sensory block than single shot spinal technique for cesarean delivery in laboring women: Anesth.Analg., v. 103, no. 6, p. 1540-1542.

Liu, S. S., and S. B. McDonald, 2001, Current issues in spinal anesthesia: Anesthesiology, v. 94, no. 5, p. 888-906.

Moiniche, S., J. B. Dahl, J. Rosenberg, and H. Kehlet, 1994, Colonic resection with early discharge after combined subarachnoid-epidural analgesia, preoperative glucocorticoids, and early postoperative mobilization and feeding in a pulmonary high-risk patient: Reg Anesth., v. 19, no. 5, p. 352-356.

Morton, G., and I. Bowler, 2001, Combined spinal-epidural as an alternative method of anaesthesia for a sigmoid-colectomy: Anaesthesia, v. 56, no. 8, p. 815-816.

Mumtaz, M. H., M. Daz, and M. Kuz, 1982, Another single space technique for orthopaedic surgery: Anaesthesia, v. 37, p. 90.

Ngan Kee, W. D., J. Shen, A. T. Chiu, I. Lok, and K. S. Khaw, 1999, Combined spinalepidural analgesia in the management of labouring parturients with mitral stenosis: Anaesth.Intensive Care, v. 27, no. 5, p. 523-526.

Norris, M. C., S. T. Fogel, and C. Conway-Long, 2001, Combined spinal-epidural versus epidural labor analgesia: Anesthesiology, v. 95, no. 4, p. 913-920.

Paech, M. J., 1997, Unexplained neurologic deficit after uneventful combined spinal and epidural anesthesia for cesarean delivery: Reg Anesth., v. 22, no. 5, p. 479-482.

Puolakka, R., M. T. Pitkanen, and P. H. Rosenberg, 2001, Comparison of technical and block characteristics of different combined spinal and epidural anesthesia techniques: Reg Anesth.Pain Med., v. 26, no. 1, p. 17-23. 
Rajakulendran, Y., S. Rahman, and N. Venkat, 1999, Long-term neurological complication following traumatic damage to the spinal cord with a 25 gauge whitacre spinal needle: Int.J.Obstet.Anesth., v. 8, no. 1, p. 62-66.

Rathmell, J. P., T. R. Lair, and B. Nauman, 2005, The role of intrathecal drugs in the treatment of acute pain: Anesth.Analg., v. 101, no. 5 Suppl, p. S30-S43.

Rawal, N., 2005, Combined spinal-epidural anaesthesia: Curr.Opin.Anaesthesiol., v. 18, no. 5, p. 518-521.

Rawal, N., B. Holmstrom, J. A. Crowhurst, and Z. A. Van, 2000, The combined spinalepidural technique: Anesthesiol.Clin.North America., v. 18, no. 2, p. 267-295.

Rawal, N., J. Schollin, and G. Wesstrom, 1988, Epidural versus combined spinal epidural block for cesarean section: Acta Anaesthesiol.Scand., v. 32, no. 1, p. 61-66.

Rawal, N., Z. A. Van, B. Holmstrom, and J. A. Crowhurst, 1997, Combined spinal-epidural technique: Reg Anesth., v. 22, no. 5, p. 406-423.

Rosenberg, P. H., 1998, Novel technology: needles, microcatheters, and combined techniques: Reg Anesth.Pain Med., v. 23, no. 4, p. 363-369.

Sandkovsky, U., M. R. Mihu, A. Adeyeye, P. M. De Forest, and J. D. Nosanchuk, 2009, Iatrogenic meningitis in an obstetric patient after combined spinal-epidural analgesia: case report and review of the literature: South.Med.J., v. 102, no. 3, p. 287-290.

Schroter, J., D. D. Wa, V. Hoffmann, A. Bach, and J. Motsch, 1997, Epidural abscess after combined spinal-epidural block: Can.J.Anaesth., v. 44, no. 3, p. 300-304.

Shnaider, R., T. Ezri, P. Szmuk, S. Larson, R. D. Warters, and J. Katz, 2001, Combined spinalepidural anesthesia for Cesarean section in a patient with peripartum dilated cardiomyopathy: Can.J.Anaesth., v. 48, no. 7, p. 681-683.

Simmons, S. W., A. M. Cyna, A. T. Dennis, and D. Hughes, 2007, Combined spinal-epidural versus epidural analgesia in labour: Cochrane.Database.Syst.Rev., no. 3, p. CD003401.

Somri, M. et al., 2011, The postoperative occurrence of cardio-respiratory adverse events in small infants undergoing gastrointestinal surgery: a prospective comparison of general anesthesia and combined spinal-epidural anesthesia: Pediatr.Surg.Int..

Somri, M., R. Tome, B. Yanovski, E. Asfandiarov, N. Carmi, J. Mogilner, B. David, and L. A. Gaitini, 2007, Combined spinal-epidural anesthesia in major abdominal surgery in high-risk neonates and infants: Paediatr.Anaesth., v. 17, no. 11, p. 1059-1065.

Soresi, A., 1937, Episubdural anesthesia: Anesthesia \& Analgesia, v. 16, no. 1-6, p. 306310.

Stamenkovic, D., V. Geric, M. Djordjevic, J. Raskovic, Z. Slavkovic, T. Randjelovic, and M. Karanikolas, 2009, Subarachnoid morphine, bupivacaine and fentanyl as part of combined spinal-epidural analgesia for low anterior resection. A prospective, randomised, double-blind clinical trial: Anaesth.Intensive Care, v. 37, no. 4, p. 552560.

Stamenkovic, D. M., V. Geric, Z. Slavkovic, J. Raskovic, and M. Djordjevic, 2008, Combined spinal-epidural analgesia vs. intermittent bolus epidural analgesia for pain relief 
after major abdominal surgery. A prospective, randomised, double-blind clinical trial: Int.J.Clin.Pract., v. 62, no. 2, p. 255-262.

Stevens, D. S., and W. T. Edwards, 1999, Management of pain in intensive care settings: Surg.Clin.North Am., v. 79, no. 2, p. 371-386.

Stienstra, R., A. Dahan, B. Z. Alhadi, J. W. van Kleef, and A. G. Burm, 1996, Mechanism of action of an epidural top-up in combined spinal epidural anesthesia: Anesth.Analg., v. 83, no. 2, p. 382-386.

Stienstra, R., B. Z. Dilrosun-Alhadi, A. Dahan, J. W. van Kleef, B. T. Veering, and A. G. Burm, 1999, The epidural "top-up" in combined spinal-epidural anesthesia: the effect of volume versus dose: Anesth.Analg., v. 88, no. 4, p. 810-814.

Tahtaci, N., and M. Neyal, 2002, Combined spinal and epidural anaesthesia in elderly patients: Int.J.Clin.Pract., v. 56, no. 9, p. 655-658.

Turner, M. A., and N. A. Reifenberg, 1995, Combined spinal epidural anaesthesia: the single space double-barrel technique: Int.J.Obstet.Anesth., v. 4, no. 3, p. 158-160.

Tyagi, A., A. Kumar, A. K. Sethi, and M. Mohta, 2008, Epidural volume extension and intrathecal dose requirement: plain versus hyperbaric bupivacaine: Anesth.Analg., v. 107, no. 1, p. 333-338.

Urmey, W. F., 2000, Combined spinal epidural anesthesia: Techniques in regional anesthesia \& pain management, v. 4, no. 1, p. 13-18.

Urmey, W. F., J. Stanton, M. Peterson, and N. E. Sharrock, 1995, Combined spinal-epidural anesthesia for outpatient surgery. Dose-response characteristics of intrathecal isobaric lidocaine using a 27-gauge Whitacre spinal needle: Anesthesiology, v. 83, no. 3, p. 528-534.

Urmey, W. F., J. Stanton, N. E. Sharrock, and E. Nigel, 1996, Combined Spinal/Epidural Anesthesia for Outpatient Surgery: Anesthesiology, v. 84, no. 2, p. 481-482.

van Zundert, A. A., G. Stultiens, J. J. Jakimowicz, D. Peek, W. G. van der Ham, H. H. Korsten, and J. A. Wildsmith, 2007, Laparoscopic cholecystectomy under segmental thoracic spinal anaesthesia: a feasibility study: Br.J.Anaesth., v. 98, no. 5, p. 682-686.

Van, d., V, N. Berends, B. Spitz, A. Teunkens, and E. Vandermeersch, 2004, Low-dose combined spinal-epidural anaesthesia vs. conventional epidural anaesthesia for Caesarean section in pre-eclampsia: a retrospective analysis: Eur.J.Anaesthesiol., v. 21, no. 6, p. 454-459.

Vasquez, C. E., R. R. Pereira, T. Tomita, A. Bedin, and R. A. Castro, 2002, [Meningitis after combined spinal-epidural analgesia for labor: case report]: Rev.Bras.Anestesiol., $\mathrm{v}$. 52, no. 3, p. 330-334.

Vassiliev, D. V., E. U. Nystrom, and C. H. Leicht, 2001, Combined spinal and epidural anesthesia for labor and cesarean delivery in a patient with Guillain-Barre syndrome: Reg Anesth.Pain Med., v. 26, no. 2, p. 174-176.

Vercauteren, M. P., K. Geernaert, D. M. Vandeput, and H. Adriaensen, 1993, Combined continuous spinal-epidural anaesthesia with a single interspace, double-catheter technique: Anaesthesia, v. 48, no. 11, p. 1002-1004.

Waegerle, J. D., 1999, Combined spinal-epidural anesthesia/analgesia: CRNA., v. 10, no. 4, p. 155-164. 
Wakamatsu, M., H. Katoh, U. Kondo, T. Yamamoto, and S. Tanaka, 1991, [Combined spinal and epidural anesthesia for orthopaedic surgery in the elderly]: Masui, v. 40, no. 12, p. 1766-1769.

Williams, R. K., W. J. McBride, and J. C. Abajian, 1997, Combined spinal and epidural anaesthesia for major abdominal surgery in infants: Can.J.Anaesth., v. 44, no. $5 \mathrm{Pt} 1$, p. $511-514$. 


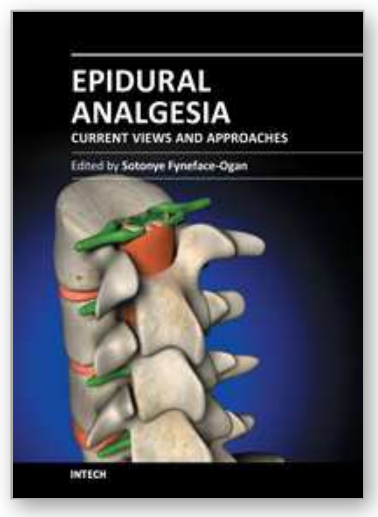

\author{
Epidural Analgesia - Current Views and Approaches \\ Edited by Dr. Sotonye Fyneface-Ogan
}

ISBN 978-953-51-0332-5

Hard cover, 174 pages

Publisher InTech

Published online 16, March, 2012

Published in print edition March, 2012

Epidural analgesia is a form of pain relief administered through the space surrounding the dural sheath either by direct injection or via catheter. The agent, when administered, can cause both a loss of sensation (anesthesia) and a loss of pain (analgesia), by reversibly interrupting the transmission of signals through nerves in or near the spinal cord. This form of pain relief has been found useful in many clinical situations. This book intends to provide an in-depth review of the current knowledge on epidural analgesia. The use of this form of analgesia is explored by contributors from different perspectives, including labor and delivery, postoperative analgesia in both pediatric and geriatric patients, and its role during anesthesia and surgery. In order to provide a balanced medical view this book was edited by an obstetric anesthesiologist.

\title{
How to reference
}

In order to correctly reference this scholarly work, feel free to copy and paste the following:

Dusica Stamenkovic and Menelaos Karanikolas (2012). Combined Spinal Epidural Anesthesia and Analgesia, Epidural Analgesia - Current Views and Approaches, Dr. Sotonye Fyneface-Ogan (Ed.), ISBN: 978-953-510332-5, InTech, Available from: http://www.intechopen.com/books/epidural-analgesia-current-views-andapproaches/combined-spinal-epidural-anesthesia-and-analgesia

\section{INTECH}

open science | open minds

\section{InTech Europe}

University Campus STeP Ri

Slavka Krautzeka 83/A

51000 Rijeka, Croatia

Phone: +385 (51) 770447

Fax: +385 (51) 686166

www.intechopen.com

\section{InTech China}

Unit 405, Office Block, Hotel Equatorial Shanghai

No.65, Yan An Road (West), Shanghai, 200040, China

中国上海市延安西路65号上海国际贵都大饭店办公楼 405 单元

Phone: +86-21-62489820

Fax: +86-21-62489821 
(C) 2012 The Author(s). Licensee IntechOpen. This is an open access article distributed under the terms of the Creative Commons Attribution 3.0 License, which permits unrestricted use, distribution, and reproduction in any medium, provided the original work is properly cited. 